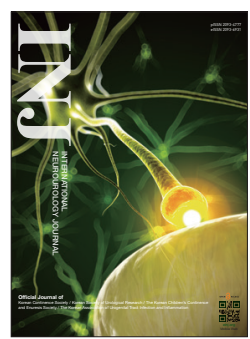

\title{
Treadmill Exercise Improves Memory Function Depending on Circadian Rhythm Changes in Mice
}

\author{
Dong Sup Hwang ${ }^{1, *}$, Hyo Bum Kwak²,*, Il Gyu Ko ${ }^{1}$, Sung Eun Kim ${ }^{1}$, Jun Jang Jin $^{1}$, Eun Sang Ji ${ }^{1}$, Hyun Hee Choi ${ }^{3}$, Oh Young Kwon ${ }^{4}$ \\ ${ }^{1}$ Department of Physiology, College of Medicine, Kyung Hee University, Seoul, Korea \\ ${ }^{2}$ Department of Kinesiology, Inha University, Incheon, Korea \\ ${ }^{3}$ Division of Leisure \& Sports Science, Department of Exercise Prescription, Dongseo University, Busan, Korea \\ ${ }^{4}$ Department of Medical Education and Medical Humanities, College of Medicine, Kyung Hee University, Seoul, Korea
}

\begin{abstract}
Purpose: Exercise enhances memory function by increasing neurogenesis in the hippocampus, and circadian rhythms modulate synaptic plasticity in the hippocampus. The circadian rhythm-dependent effects of treadmill exercise on memory function in relation with neurogenesis were investigated using mice.

Methods: The step-down avoidance test was used to evaluate short-term memory, the 8-arm maze test was used to test spatial learning ability, and 5-bromo-2'-deoxyuridine immunofluorescence was used to assess neurogenesis. Western blotting was also performed to assess levels of synaptic plasticity-associated proteins, such as brain-derived neurotrophic factor, tyrosine kinase receptor B, phosphorylated cAMP response element-binding protein, early growth response protein 1, postsynaptic density protein 95, and growth-associated protein 43 . The mice in the treadmill exercise at zeitgeber 1 group started exercising 1 hour after sunrise, the mice in the treadmill exercise at zeitgeber 6 group started exercising 6 hours after sunrise, and the mice in the treadmill exercise at zeitgeber 13 group started exercising 1 hour after sunset. The mice in the exercise groups were forced to run on a motorized treadmill for 30 minutes once a day for 7 weeks.

Results: Treadmill exercise improved short-term memory and spatial learning ability, and increased hippocampal neurogenesis and the expression of synaptic plasticity-associated proteins. These effects of treadmill exercise were stronger in mice that exercised during the day or in the evening than in mice that exercised at dawn.

Conclusions: Treadmill exercise improved memory function by increasing neurogenesis and the expression of synaptic plasticity-associated proteins. These results suggest that the memory-enhancing effect of treadmill exercise may depend on circadian rhythm changes.
\end{abstract}

Keywords: Exercise Test; Memory, Short-term; Learning; Neurogenesis; Neuronal Plasticity

- Grant Support: This research was supported by Basic Science Research Program through the National Research Foundation of Korea (NRF) funded by the Ministry of Education, Science and Technology (2012R1A1A1042383).

- Research Ethics: All experiments were performed in accordance with the animal care guidelines of the National Institutes of Health and the Korean Academy of Medical Sciences.

- Conflict of Interest: No potential conflict of interest relevant to this article was reported.

\section{INTRODUCTION}

Treadmill exercise exerts neuroprotective effects through en- hancing neurogenesis and inhibiting apoptotic neuronal cell death in the hippocampus, thus ameliorating memory impairments [1-4]. Treadmill exercise also enhances memory func-
Corresponding author: Oh Young Kwon (iD http://orcid.org/0000-0003-0817-2256 Department of Medical Education and Medical Humanities, College of Medicine, Kyung Hee University, 26 Kyungheedae-ro, Dongdaemun-gu, Seoul 02447, Korea E-mail: koy0004@hotmail.com / Tel: +82-2-961-9102 / Fax: +82-2-961-9573

* Dong Sup Hwang and Hyo Bum Kwak contributed equally to this study as co-first authors. Submitted: October 11, 2016 / Accepted after revision: October 24, 2016
This is an Open Access article distributed under the terms of the Creative Commons Attribution Non-Commercial License (http://creativecommons.org/licenses/by-nc/4.0/) which permits unrestricted non-commercial use, distribution, and reproduction in any medium, provided the original work is properly cited. 
tion by enhancing hippocampal synaptic plasticity under normal conditions [5-7]. Synaptic plasticity in the hippocampus is associated with many proteins, including brain-derived neurotrophic factor (BDNF), tyrosine kinase receptor B (TrkB), cAMP response element-binding protein (CREB), early growth response protein-1 (Egr-1), postsynaptic density protein 95 (PSD95), and growth-associated protein 43 (GAP43).

$\mathrm{BDNF}$ is a key structure for plasticity-related events in the nervous system. BDNF is stimulated by the activation of CREB via the $\operatorname{TrkB}$ receptor, and then enhances synaptic transmission $[8,9]$. BDNF-induced $\operatorname{TrkB}$ phosphorylation then activates the mitogen-activated protein kinase cascade during long-term potentiation (LTP) [9].

Egr-1, PSD-95, and GAP43 are the major elements involved in memory formation. Egr-1 is essential for stabilizing synaptic plasticity in the hippocampus as well as for LTP [10]. PSD95 is abundantly expressed in the excitatory synapses and is linked to the enhancement of long-term memory [11]. GAP43 is expressed at high levels in neuronal growth cones during development and axonal regeneration, and it is phosphorylated after LTP and the learning process [12].

Circadian rhythms regulate hippocampal excitability and LTP, and the endogenous circadian oscillator modulates synaptic plasticity in the hippocampus [13]. Disruption of circadian rhythms affects the baseline activity of the stress system, and alters responses to subsequent stressors [14]. Circadian rhythms are important for the determination of sleeping and feeding patterns in most animals, including humans [15].
The effects of exercise on brain function are well documented; however, the circadian rhythm-dependent effect of treadmill exercise on memory function has not been explored. In the present study, we investigated the circadian rhythm dependence of the effects of treadmill exercise on memory function in relation with neurogenesis using mice. In this study, the stepdown avoidance test, 8-arm maze test, immunofluorescence for 5-bromo-2'-deoxyuridine (BrdU), and western blotting for BDNF, TrkB, phosphorylated CREB (p-CREB), Egr-1, PSD95, and GAP43 were performed.

\section{MATERIALS AND METHODS}

\section{Animals and Treatments}

Male C57BL/6N mice (8 weeks old; weighing $20 \pm 1 \mathrm{~g}$ ) were used and experimental procedures were performed in accordance with the animal care guidelines of the National Institutes of Health and the Korean Academy of Medical Sciences. The mice were divided into 4 groups $(n=12)$ : the control group, the treadmill exercise at zeitgeber 1 (ZT1-Ex) group, the treadmill exercise at zeitgeber 6 (ZT6-Ex) group, and the treadmill exercise at zeitgeber 13 (ZT13-Ex) group. Zeitgeber refers to environmental time cues that train biological rhythms to a specific periodicity. The mice in the ZT1-Ex group started exercising 1 hour after sunrise, the mice in the ZT6-Ex group started exercising 6 hours after sunrise, and the mice in the ZT13-Ex group started exercising 1 hour after sunset (Fig. 1).

All mice received $50 \mathrm{mg} / \mathrm{kg}$ of BrdU (Sigma Chemical Co., St.

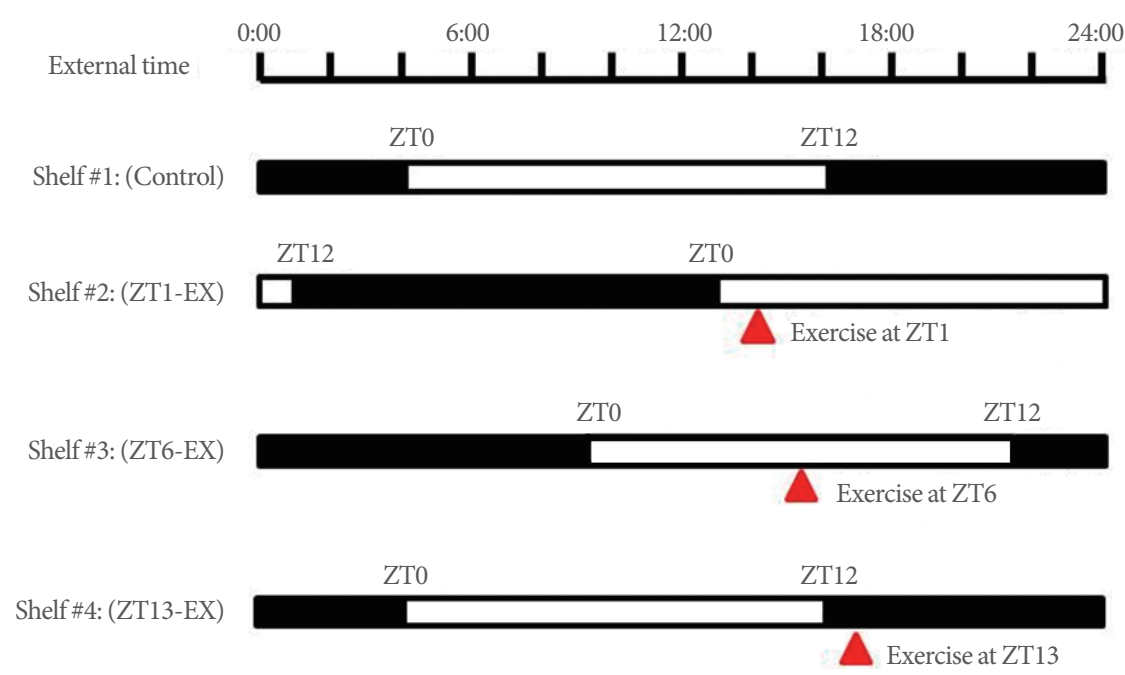

Fig. 1. Treadmill exercise protocols. Control, control group; ZT1-Ex, treadmill exercise at zeitgeber 1 group; ZT6-Ex, treadmill exercise at zeitgeber 6 group; ZT13-Ex, treadmill exercise at zeitgeber 13 group. 
Louis, MO, USA) intraperitoneally once a day 30 minutes before the start of the treadmill exercise during the first 2 weeks. The mice in the exercise groups were forced to run on a motorized treadmill (Columbus Instruments, Columbus, OH, USA) for 30 minutes once a day for 7 weeks. The exercise load consisted of running at a speed of $8 \mathrm{~m} / \mathrm{min}$ with a $0^{\circ}$ inclination.

\section{Step-Down Avoidance Test}

The latency of the step-down avoidance test was determined to evaluate short-term memory, according to previously described methodology $[2,8]$. The mice were trained in a step-down avoidance test 46 days after starting treadmill exercise. The mice were placed on a $7 \times 25-\mathrm{cm}$ platform $2.5 \mathrm{~cm}$ high. The platform faced a $42 \times 25-\mathrm{cm}$ grid of parallel $0.1-\mathrm{cm}$ caliber stainless steel bars spaced $1 \mathrm{~cm}$ apart. In the training session, the animals received a $0.5-\mathrm{mA}$ scramble foot shock for 2 seconds immediately upon stepping down. One day after training, the latency (seconds) was determined. The interval of mice stepping down and placing all four paws on the grid was defined as the latency time. Latencies over 300 seconds were counted as 300 seconds.

\section{Radial 8-Arm Maze Test}

Spatial learning ability was tested using a radial 8-arm maze apparatus, following previously described methodology $[1,2]$. The radial-arm maze apparatus consisted of a central octagonal plate (30 $\mathrm{cm}$ in diameter) and 8 radiating arms $(50 \mathrm{~cm}$ in length and $10 \mathrm{~cm}$ in width). The apparatus was placed $1 \mathrm{~m}$ above the floor. A small receptacle filled with water $(3 \mathrm{~cm}$ in diameter and $1 \mathrm{~cm}$ in depth) was located at the end of the arms. The mice were trained 3 times before the test. The mice were deprived of water for 24 hours and then were allowed to explore for water for 5 minutes. The test was conducted 48 days after starting the treadmill exercise. The time spent seeking water at the end of the arm was measured. The test was terminated when a mouse found water in all 8 arms or when 8 minutes elapsed. Re-entry into previously visited arms was counted as an error. The number of correct choices before the first error was counted.

\section{Tissue Preparation}

The mice were sacrificed immediately after performing the radial 8-arm maze test. The animals were anesthetized using Zoletil $50(10 \mathrm{mg} / \mathrm{kg}$, intraperitoneally; Vibac Laboratories, Carros, France), transcardially perfused with $50 \mathrm{mM}$ phosphatebuffered saline (PBS), and fixed with a freshly prepared solution consisting of $4 \%$ paraformaldehyde in $100 \mathrm{mM}$ phosphate buffer $(\mathrm{pH}, 7.4)$. Coronal sections $40 \mu \mathrm{m}$ in thickness were made using a freezing microtome (Leica, Nussloch, Germany).

\section{Immunofluorescence for BrdU and Neuronal Nuclei}

Double immunofluorescence for BrdU and neuronal nuclei (NeuN) was conducted, according to a previously described method [2,4]. After washing, the sections were incubated in blocking solution, and then were incubated with rat monoclonal anti-BrdU antibody (1:300, Abcam, Cambridge, MA, USA) and mouse monoclonal anti-NeuN antibody (1:300, Chemicon International, Temecula, CA, USA) overnight at $4^{\circ} \mathrm{C}$. The sections were incubated in Cy3-conjugated goat anti-rat IgG (1:300, Jackson ImmunoResearch Laboratories Inc., West Grove, PA, USA) and fluorescein isothiocyanate (FICT)-conjugated goat antimouse IgG (1:300, Jackson ImmunoResearch Laboratories Inc.). Next, the sections were washed three times with PBS, and then mounted with fluorescent mount medium (DakoCytomation, Carpinteria, CA, USA).

\section{Western Blot Analysis}

Western blotting was conducted according to previously published methodology $[8,16]$. The hippocampal tissues were homogenized on ice and lysed in a lysis buffer. Protein $(30 \mu \mathrm{g})$ was separated on sodium dodecyl sulfate-polyacrylamide gels and transferred onto a nitrocellulose membrane. Mouse beta-actin antibody (1:1,000; Santa Cruz Biotechnology, Santa Cruz, CA, USA), mouse GAP43 antibody (1:1,000; Santa Cruz Biotechnology), rabbit BDNF antibody (1:500; Santa Cruz Biotechnology), rabbit TrkB antibody (1:1,000; Santa Cruz Biotechnology), rabbit PSD95 antibody (1:1,000; Santa Cruz Biotechnology), rabbit Egr-1 antibody (1:1,000; Santa Cruz Biotechnology), and goat pCREB antibody (1:1,000; Santa Cruz Biotechnology) were used as the primary antibodies. Horseradish peroxidase-conjugated anti-rabbit antibody for BDNF, TrkB, PSD95, and Egr-1 (1:3,000; Vector Laboratories, Burlingame, CA, USA), horseradish peroxidase-conjugated anti-mouse antibody for beta-actin and GAP43 (1:2,000; Vector Laboratories), and horseradish peroxidase-conjugated anti-goat antibody for p-CREB (1:5,000; Santa Cruz Biotechnology) were used as the secondary antibodies. Band detection was conducted using an enhanced chemiluminescence detection kit (Santa Cruz Biotechnology).

\section{Data Analysis}

The area of the hippocampal dentate gyrus was measured using 
the Image-Pro Plus computer-assisted image analysis system (Media Cyberbetics Inc., Silver Spring, MD, USA). The BrdUpositive cells in the hippocampal dentate gyrus were counted hemilaterally through a light microscope (Olympus, Tokyo, Japan). The mean numerical density, $N_{v}$, of the BrdU-positive cells was calculated according to the sum of the counts made within the granular regions of each section, as well as the volume of the granular regions included in each section. The total number of BrdU-positive cells in the granular layer, $N$, was then calculated by multiplication of the numerical density of BrdUpositive cells, $N v$, by the reference volume $\left(\mathrm{mm}^{3}\right), V_{\text {ref, }}$ using the formula $N=N_{\mathrm{v}} \times V_{\text {ref. }} V_{\text {ref }}$ was estimated according to Cavalieris method [17], resulting in the equation $V_{\text {ref }}=a \times t \times s$, where $a$ represents the mean area of the granular cell layer, $t$ is the mean thickness of the microtome section $(40 \mu \mathrm{m})$, and $s$ is the total number of sections through the reference volume. For the relative expression of proteins in western blot analysis, the detected
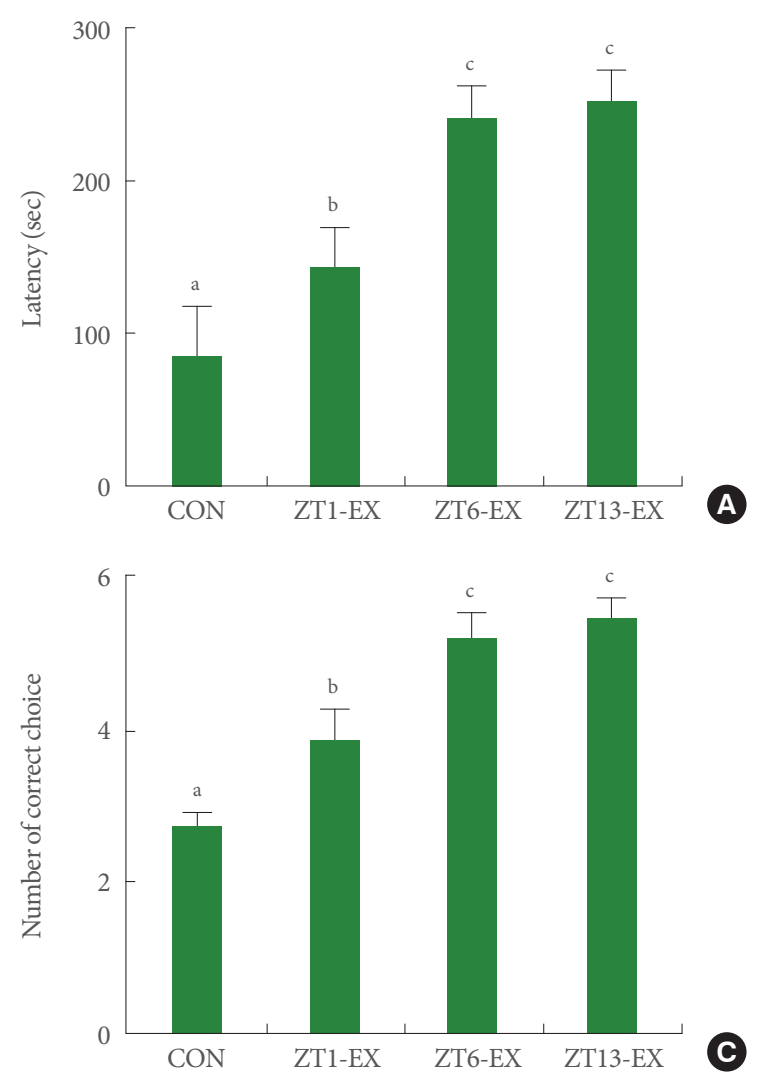

bands were calculated densitometrically using Molecular Analyst ver. 1.4.1 (Bio-Rad, Hercules, CA, USA).

Statistical analysis was performed using one-way analysis of variance followed by Duncan post hoc test, and the results are expressed as the mean \pm standard error of the mean. Significance was set as $\mathrm{P}<0.05$.

\section{RESULTS}

\section{Circadian Rhythm-Dependent Effects of Treadmill Exercise on Short-term Memory}

Latency was higher in the treadmill exercise groups than in the control group; moreover, latency in the ZT6-Ex group and in the ZT13-Ex group was higher than in the ZT1-Ex group (Fig. 2A). Treadmill exercise improved short-term memory, and this effect was more potent in mice who exercised during the day or in the evening than at dawn.
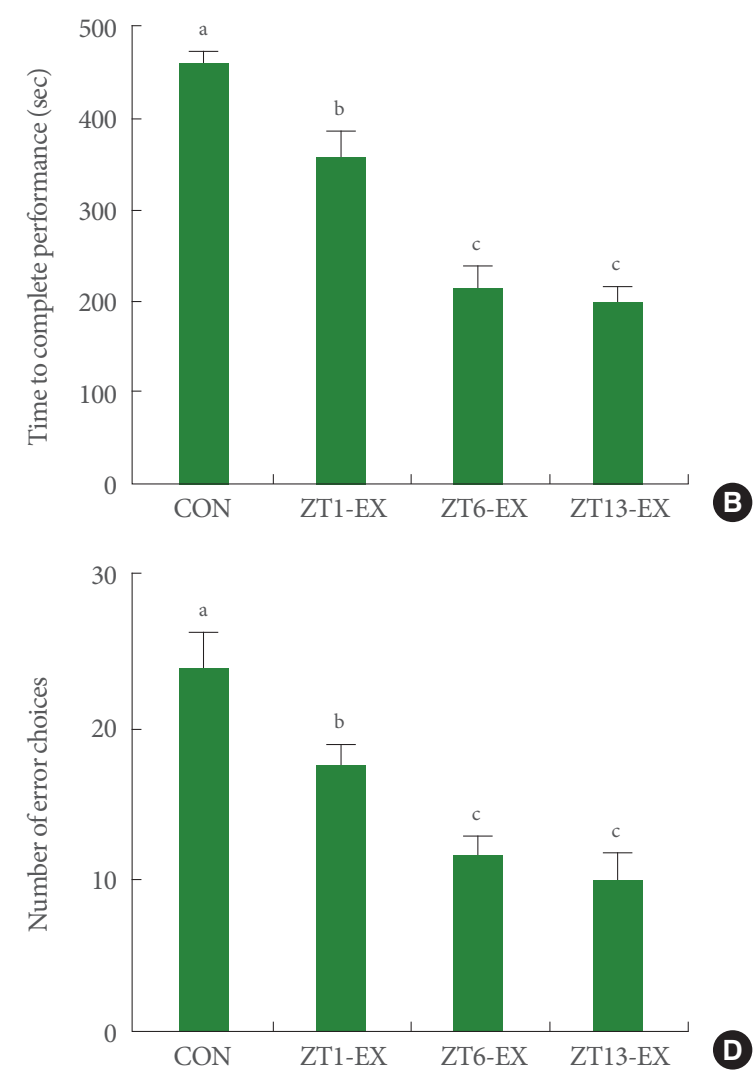

Fig. 2. Effects of treadmill exercise on short-term memory and spatial learning ability. (A) Latency in the step-down avoidance test. (B) Time to complete performance in the radial 8-arm maze test. (C) Number of correct choices in the radial 8-arm maze test. (D) Number of erroneous choices in the radial 8-arm maze test. CON, control group; ZT1-Ex, treadmill exercise at zeitgeber 1 group; ZT6-Ex, treadmill exercise at zeitgeber 6 group; ZT13-Ex, treadmill exercise at zeitgeber 13 group. Different letters (a-c) denote statistically significant differences. 


\section{Circadian Rhythm-Dependent Effects of Treadmill Exercise on Spatial Learning Ability}

The time to complete performance was shorter in the treadmill exercise groups than in the control group; moreover, this time was shorter in the ZT6-Ex group and in the ZT13-Ex group than in the ZT1-Ex group (Fig. 2B). The number of correct choices was higher in the treadmill exercise groups than in the
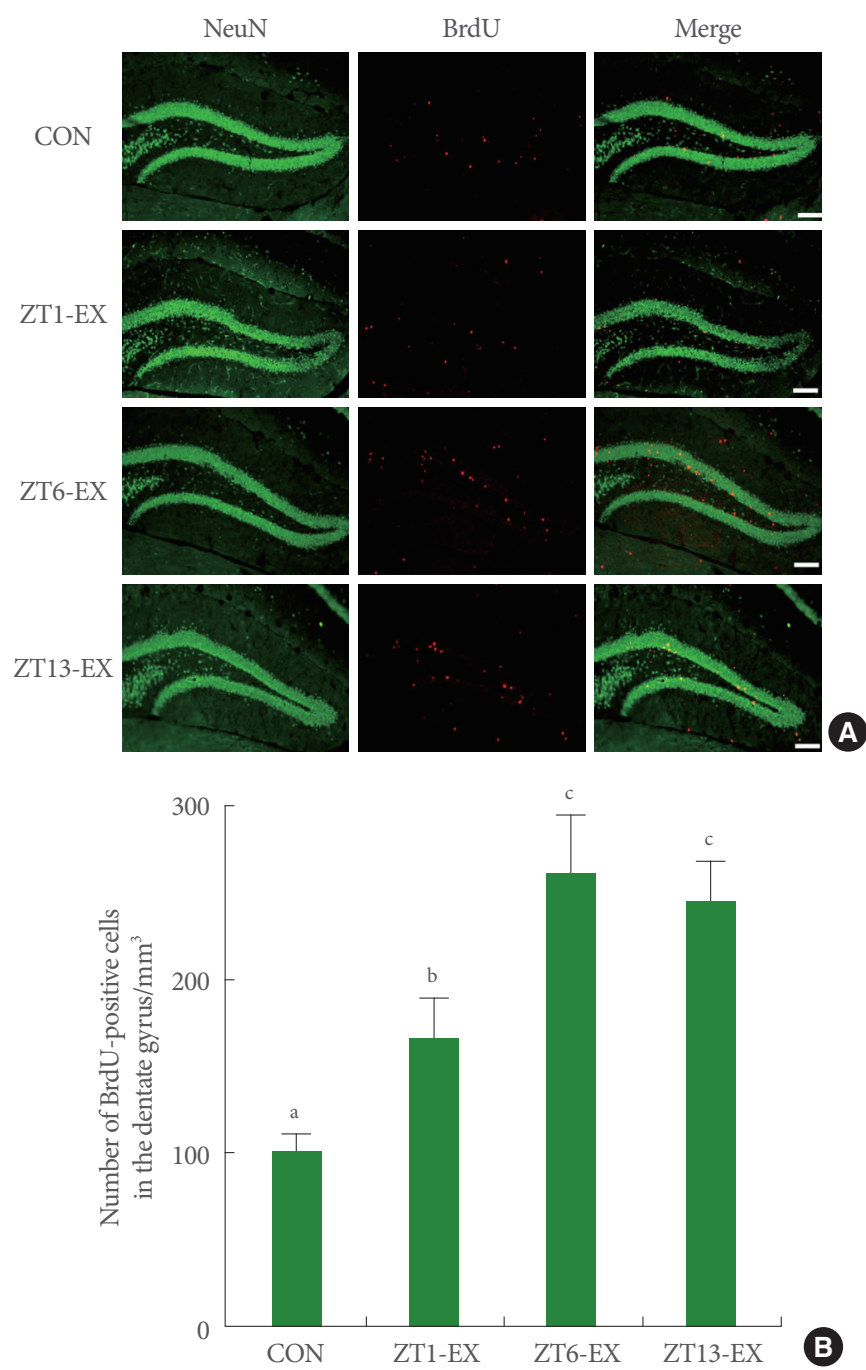

Fig. 3. Effects of treadmill exercise on neurogenesis in the hippocampal dentate gyrus. (A) Photomicrographs of BrdU-positive cells in the hippocampal dentate gyrus region. The scale bar represents $200 \mu \mathrm{m}$. (B) Number of BrdU-positive cells in each group. CON, control group; ZT1-Ex, treadmill exercise at zeitgeber 1 group; ZT6-Ex, treadmill exercise at zeitgeber 6 group; ZT13-Ex, treadmill exercise at zeitgeber 13 group; NeuN, neuronal nuclei; BrdU, 5-bromo-2'-deoxyuridine. Different letters (a-c) denote statistically significant differences. control group, and this number was higher in the ZT6-Ex group and in the ZT13-Ex group than in the ZT1-Ex group (Fig. 2C). The number of erroneous choices was lower in the treadmill exercise groups than in the control group, and this number was lower in the ZT6-Ex group and in the ZT13-Ex group than in the ZT1-Ex group (Fig. 2D). Treadmill exercise improved spatial learning ability, and this effect was more potent in mice who exercised during the day or in the evening than at dawn.

\section{Circadian Rhythm-Dependent Effects of Treadmill Exercise on Neurogenesis}

Photomicrographs of BrdU-positive cells in the hippocampal dentate gyrus are presented in Fig. 3. The number of BrdUpositive cells was higher in the treadmill exercise groups than in the control group, and this number was higher in the ZT6Ex group and in the ZT13-Ex group than in the ZT1-Ex group (Fig. 3). Treadmill exercise increased hippocampal neurogenesis, and this effect was more potent in mice who exercised during the day or in the evening than at dawn.

\section{Circadian Rhythm-Dependent Effects of Treadmill Exercise on BDNF, TrkB, p-CREB, Egr-1, PSD95, and GAP43 Expression}

BDNF expression in the hippocampus was greater in the treadmill exercise groups than in the control group, and this increase was greater in the ZT6-Ex group and in the ZT13-Ex group than in the ZT1-Ex group (Fig. 4A). TrkB expression in the hippocampus was greater in the treadmill exercise groups than in the control group; however, no differences were found among the exercise groups (Fig. 4B). p-CREB expression in the hippocampus was greater in the in the ZT6-Ex group and in the ZT13-Ex group than the control group, but this effect was not found in the ZT1-Ex group (Fig. 4C). Egr-1 expression in the hippocampus was greater in the in the ZT6-Ex group and in the ZT13-Ex group than in the control group, but this effect was not found in the ZT1-Ex group (Fig. 4D). PSD95 expression in the hippocampus was greater in the treadmill exercise groups than in the control group, and this increase was greater in the ZT6-Ex group and in the ZT13-Ex group than in the ZT1-Ex group (Fig. 4E). GAP43 expression in the hippocampus was greater in the in the ZT6-Ex group and in the ZT13-Ex group than in the control group, but this effect was not found in the ZT1-Ex group (Fig. 4F). Treadmill exercise increased the expression of hippocampal plasticity-associated proteins, and this effect was more potent in mice who exercised during the 
CON ZT1-EX ZT6-EX ZT13-EX
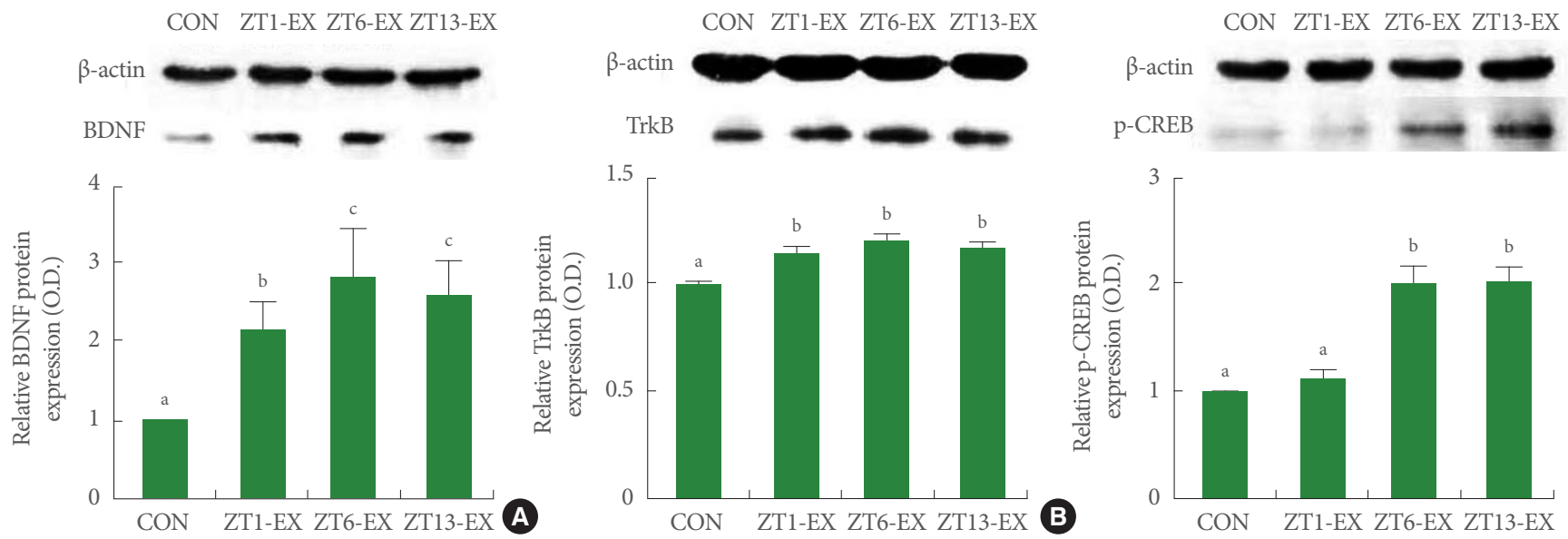

CON ZT1-EX ZT6-EX ZT13-EX
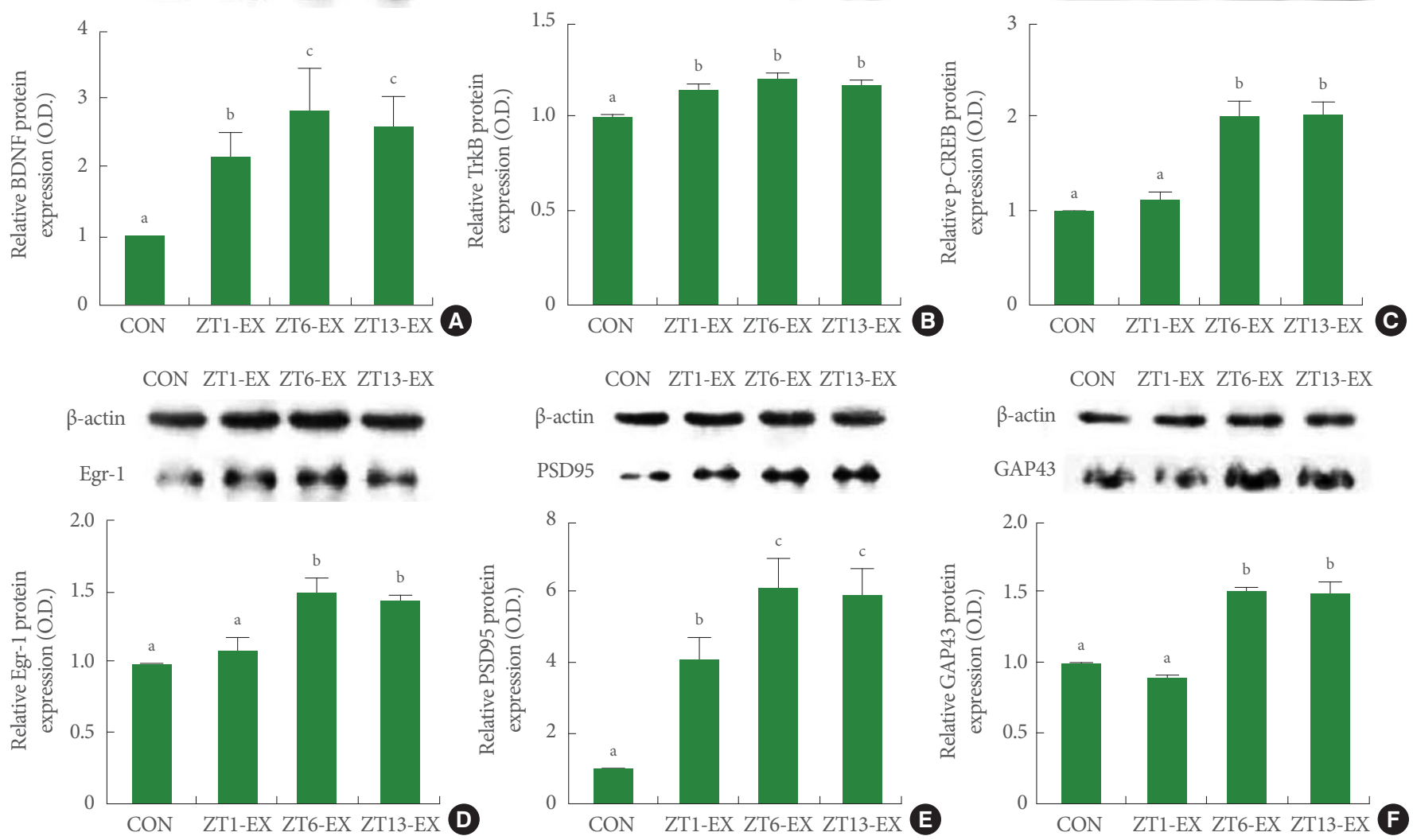

Fig. 4. Effects of treadmill exercise on synaptic plasticity-associated proteins in the hippocampus. Beta-actin was used as an internal control (46 kDa). (A) BDNF expression. (B) TrkB expression. (C) p-CREB expression. (D) Egr-1 expression. (E) PSD95 expression. (F) GAP43 expression. CON, control group; ZT1-Ex, treadmill exercise at zeitgeber 1 group; ZT6-Ex, treadmill exercise at zeitgeber 6 group; ZT13-Ex, treadmill exercise at zeitgeber 13 group; BDNF, brain-derived neurotrophic factor; TrkB, tyrosine kinase receptor B; p-CREB, phosphorylated cAMP response element-binding protein; Egr-1, early growth response protein 1; PSD95, postsynaptic density protein 95; GAP43, growth-associated protein 43. Different letters (a-c) denote statistically significant differences.

day or in the evening than at dawn.

\section{DISCUSSION}

Disruptions of circadian rhythm affect health [18]. Dyssynchrony of circadian rhythms contributes to the pathogenesis of cardiovascular diseases [19]. The neuroprotective effect of exercise is influenced by circadian rhythm changes [20], and circadian variation has also been found to affect micturition patterns in healthy female nurses [21].

In the present study, the mice ran on the treadmill at different times: dawn, daytime, and evening. Short-term memory and spatial learning ability were improved by treadmill exercise, and this effect was more potent in mice who exercised during the day or in the evening than at dawn.

It is well documented that treadmill exercise improves memory function [1-3,8]. Chaudhury et al. [13] suggested that the endogenous circadian oscillator may be closely implicated in hippocampal synaptic plasticity. Long-term disruption of circadian rhythms was found to induce alterations in synaptic plasticity, suppressed hippocampal cell proliferation, and shortened cell survival, resulting in cognitive dysfunction and mood disorders [22]. Our current results showed that the positive effect of treadmill exercise on memory function depended on circadian rhythm changes.

In the present study, the number of BrdU-positive cells in the 
hippocampal dentate gyrus was enhanced by performing treadmill exercise, and this effect was more potent in mice who exercised during the day or in the evening than at dawn.

Treadmill exercise enhances neurogenesis in the hippocampal dentate gyrus $[1,2,8,23,24]$. Voluntary exercise-induced neurogenesis in mice has been associated with increased synaptic plasticity [5]. The positive effect of treadmill exercise on the number of BrdU-positive cells in the hippocampal dentate gyrus has been found to exhibit a positive relation with hippocampal plasticity [25]. Enhanced neurogenesis by exercise is closely implicated in the improvement of learning ability and memory capability $[2,8,23,24]$. The number of BrdU-positive cells in the hippocampal dentate gyrus has been found to fluctuate across the light-dark cycle [26]. Our present results showed that the enhancing effect of treadmill exercise on neurogenesis was affected by circadian rhythm changes.

We found that BDNF and p-CREB expression in the hippocampus was enhanced by performing treadmill exercise, and that this effect was more potent in mice who exercised during the day or in the evening than at dawn.

BDNF modulates neurotransmitter release, stimulates vesicle-associated proteins, and regulates the expression of transcriptional factors [27]. Transcriptional activation of the BDNF gene is commonly regulated by a key transcription factor, $\mathrm{CREB}$, and this activation at least in part contributes to neuronal survival [28]. BDNF is an important intercellular signal mediating neurogenesis, synaptic plasticity, and cell survival [29]. Treadmill exercise has been found to reverse stress-induced changes in the rat hippocampus through BDNF upregulation via increasing phosphoinositide 3-kinase (PI3K)/protein kinase $\mathrm{B}$ (Akt) signaling [30]. Activation of PI3K/Akt signaling inhibited neuronal apoptosis [16]. Short bouts of exercise have been found to improve cognition by enhancing BDNF expression through activation of Akt and CREB signaling in the hippocampus of aging rats [31]. Treadmill exercise has been found to increase BDNF and TrkB expression through p-CREB expression [23].

In the current study, Egr-1 and GAP43 expression in the hippocampus was enhanced by exercising during the day or in the evening in comparison to not exercising or exercising at dawn. PSD95 expression in the hippocampus was enhanced by performing treadmill exercise, and this effect was more potent in mice who exercised during the day or in the evening than at dawn.

LTP is highly correlated with the increased expression of
Egr-1 [10]. GAP43 and PSD95 are synaptic plasticity factors controlling synaptic strength, and these factors are enhanced by physical exercise [32,33]. Interactions of nerve growth factor, calmodulin, protein kinase C, and GAP43 have been found to be related to the underlying mechanisms of exercise-induced paralysis recovery [33]. Presynaptic proteins, such as synaptosomal associated protein-25, and postsynaptic proteins, such as the NR2B subunit of $N$-methyl-D-aspartate receptors and PSD95, are strongly implicated in exercise-induced improvements in cognition [32]. Our results showed that the enhancing effect of treadmill exercise on the expression of synaptic plasticity-associated proteins was influenced by circadian rhythm changes.

Zeitgeber refers to an external biological rhythm in response to which endogenous cycles cue various actions in plants and animals. Light, melatonin, and physical activity are well known zeitgebers. In this study, we used light as the zeitgeber. In the present study, treadmill exercise improved memory function through increasing neurogenesis and expression of synaptic plasticity-associated proteins. These effects of treadmill exercise were stronger when exercising at daytime or evening than when exercising at dawn. Our results suggest that the memoryenhancing effect of exercise is dependent on circadian rhythm changes. As humans are diurnal and mice are nocturnal, however, the present results might apply to humans in reverse; that is, the memory-enhancing effects of exercise might be most potent when exercising at dawn in humans. Further studies are needed to evaluate this possibility.

\section{REFERENCES}

1. Baek SS, Jun TW, Kim KJ, Shin MS, Kang SY, Kim CJ. Effects of postnatal treadmill exercise on apoptotic neuronal cell death and cell proliferation of maternal-separated rat pups. Brain Dev 2012; 34:45-56.

2. Kim SE, Ko IG, Kim BK, Shin MS, Cho S, Kim CJ, et al. Treadmill exercise prevents aging-induced failure of memory through an increase in neurogenesis and suppression of apoptosis in rat hippocampus. Exp Gerontol 2010;45:357-65.

3. Kim K, Sung YH, Seo JH, Lee SW, Lim BV, Lee CY, et al. Effects of treadmill exercise-intensity on short-term memory in the rats born of the lipopolysaccharide-exposed maternal rats. J Exerc Rehabil 2015;11:296-302.

4. Shin MS, Ko IG, Kim SE, Kim BK, Kim TS, Lee SH, et al. Treadmill exercise ameliorates symptoms of methimazole-induced hypothy- 
roidism through enhancing neurogenesis and suppressing apoptosis in the hippocampus of rat pups. Int J Dev Neurosci 2013;31:21423.

5. Farmer J, Zhao X, van Praag H, Wodtke K, Gage FH, Christie BR. Effects of voluntary exercise on synaptic plasticity and gene expression in the dentate gyrus of adult male Sprague-Dawley rats in vivo. Neuroscience 2004;124:71-9.

6. O'Callaghan RM, Ohle R, Kelly AM. The effects of forced exercise on hippocampal plasticity in the rat: a comparison of LTP, spatialand non-spatial learning. Behav Brain Res 2007;176:362-6.

7. Vasuta C, Caunt C, James R, Samadi S, Schibuk E, Kannangara T, et al. Effects of exercise on NMDA receptor subunit contributions to bidirectional synaptic plasticity in the mouse dentate gyrus. Hippocampus 2007;17:1201-8.

8. Kim YM, Ji ES, Kim SH, Kim TW, Ko IG, Jin JJ, et al. Treadmill exercise improves short-term memory by enhancing hippocampal cell proliferation in quinolinic acid-induced Huntington's disease rats. J Exerc Rehabil 2015;11:5-11.

9. Tabuchi A, Sakaya H, Kisukeda T, Fushiki H, Tsuda M. Involvement of an upstream stimulatory factor as well as cAMP-responsive element-binding protein in the activation of brain-derived neurotrophic factor gene promoter I. J Biol Chem 2002;7:35920-31.

10. Williams JM, Beckmann AM, Mason-Parker SE, Abraham WC, Wilce PA, Tate WP. Sequential increase in Egr-1 and AP-1 DNA binding activity in the dentate gyrus following the induction of long-term potentiation. Brain Res Mol Brain Res 2000;77:258-66.

11. Radwanska K, Medvedev NI, Pereira GS, Engmann O, Thiede N, Moraes MF, et al. Mechanism for long-term memory formation when synaptic strengthening is impaired. Proc Natl Acad Sci U S A 2011;108:18471-5.

12. Routtenberg A. Adult learning and remodeling of hippocampal mossy fibers: unheralded participant in circuitry for long-lasting spatial memory. Hippocampus 2010;20:44-5.

13. Chaudhury D, Wang LM, Colwell CS. Circadian regulation of hippocampal long-term potentiation. J Biol Rhythms 2005;20:225-36.

14. Sgoifo A, Buwalda B, Roos M, Costoli T, Merati G, Meerlo P. Effects of sleep deprivation on cardiac autonomic and pituitary-adrenocortical stress reactivity in rats. Psychoneuroendocrinology 2006; 31:197-208.

15. Wang G, Grone B, Colas D, Appelbaum L, Mourrain P. Synaptic plasticity in sleep: learning, homeostasis and disease. Trends Neurosci 2011;34:452-63.

16. Kim M, Shin MS, Lee JM, Cho HS, Kim CJ, Kim YJ, et al. Inhibitory effects of isoquinoline alkaloid berberine on ischemia-induced apoptosis via activation of phosphoinositide 3-kinase/protein ki- nase B signaling pathway. Int Neurourol J 2014;18:115-25.

17. Kempermann G, Kuhn HG, Gage FH. Genetic influence on neurogenesis in the dentate gyrus of adult mice. Proc Natl Acad Sci U S A 1997;94:10409-14.

18. Persson M, Mårtensson J. Situations influencing habits in diet and exercise among nurses working night shift. J Nurs Manag 2006;14: 414-23.

19. Durgan DJ, Young ME. The cardiomyocyte circadian clock: emerging roles in health and disease. Circ Res 2010;106:647-58.

20. Elsner VR, Lovatel GA, Bertoldi K, Vanzella C, Santos FM, Spindler $\mathrm{C}$, et al. Effect of different exercise protocols on histone acetyltransferases and histone deacetylases activities in rat hippocampus. Neuroscience 2011;192:580-7.

21. Kim KT, Kim CH, Kwon B, Han DH, Yoon SJ, Cho S, et al. Do rotational shifts affect micturition patterns in real practice? A pilot study in healthy, young female nurses. Int Neurourol J 2014;18:20612.

22. Meerlo P, Mistlberger RE, Jacobs BL, Heller HC, McGinty D. New neurons in the adult brain: the role of sleep and consequences of sleep loss. Sleep Med Rev 2009;13:187-94.

23. Seo TB, Kim TW, Shin MS, Ji ES, Cho HS, Lee JM, et al. Aerobic exercise alleviates ischemia-induced memory impairment by enhancing cell proliferation and suppressing neuronal apoptosis in hippocampus. Int Neurourol J 2014;18:187-97.

24. van Praag H, Shubert T, Zhao C, Gage FH. Exercise enhances learning and hippocampal neurogenesis in aged mice. J Neurosci 2005;25:8680-5.

25. Ferreira AF, Real CC, Rodrigues AC, Alves AS, Britto LR. Shortterm, moderate exercise is capable of inducing structural, BDNFindependent hippocampal plasticity. Brain Res 2011;1425:111-22.

26. Kochman LJ, Weber ET, Fornal CA, Jacobs BL. Circadian variation in mouse hippocampal cell proliferation. Neurosci Lett 2006;406: 256-9.

27. Bolton MM, Lo DC, Sherwood NT. Long-term regulation of excitatory and inhibitory synaptic transmission in hippocampal cultures by brain-derived neurotrophic factor. Prog Brain Res 2000; 128:203-18.

28. Tabuchi A. Synaptic plasticity-regulated gene expression: a key event in the long-lasting changes of neuronal function. Biol Pharm Bull 2008;31:327-35.

29. Lee E, Son H. Adult hippocampal neurogenesis and related neurotrophic factors. BMB Rep 2009;42:239-44.

30. Fang ZH, Lee CH, Seo MK, Cho H, Lee JG, Lee BJ, et al. Effect of treadmill exercise on the BDNF-mediated pathway in the hippocampus of stressed rats. Neurosci Res 2013;76:187-94. 
31. Aguiar AS Jr, Castro AA, Moreira EL, Glaser V, Santos AR, Tasca $\mathrm{CI}$, et al. Short bouts of mild-intensity physical exercise improve spatial learning and memory in aging rats: involvement of hippocampal plasticity via AKT, CREB and BDNF signaling. Mech Ageing Dev 2011;132:560-7.

32. Hu S, Ying Z, Gomez-Pinilla F, Frautschy SA. Exercise can increase small heat shock proteins (sHSP) and pre- and post-synaptic proteins in the hippocampus. Brain Res 2009;1249:191-201.

33. Mizutani K, Sonoda S, Yamada K, Beppu H, Shimpo K. Alteration of protein expression profile following voluntary exercise in the perilesional cortex of rats with focal cerebral infarction. Brain Res 2011;1416:61-8. 